\title{
A Prototype Quantitative Precipitation Estimation Algorithm for Operational S-Band Polarimetric Radar Utilizing Specific Attenuation and Specific Differential Phase. Part II: Performance Verification and Case Study Analysis
}

\author{
Stephen B. Cocks, Lin TAng, Pengfei Zhang, Alexander Ryzhkov, \\ BRIAN KANEY, AND KIMBERLY L. ELMORE \\ Cooperative Institute for Mesoscale Meteorological Studies, University of Oklahoma, and \\ NOAA/OAR National Severe Storms Laboratory, Norman, Oklahoma \\ YADONG WANG \\ Department of Electrical and Computer Engineering, Southern Illinois University Edwardsville, \\ Edwardsville, Illinois, and Cooperative Institute for Mesoscale Meteorological Studies, University \\ of Oklahoma, and NOAA/OAR/National Severe Storms Laboratory, Norman, Oklahoma
}

JIAN ZHANG AND KENNETH HOWARD

NOAA/OAR National Severe Storms Laboratory, Norman, Oklahoma

(Manuscript received 10 April 2018, in final form 23 February 2019)

\begin{abstract}
The quantitative precipitation estimate (QPE) algorithm developed and described in Part I was validated using data collected from 33 Weather Surveillance Radar 1988-Doppler (WSR-88D) radars on 37 calendar days east of the Rocky Mountains. A key physical parameter to the algorithm is the parameter alpha $\alpha$, defined as the ratio of specific attenuation $A$ to specific differential phase $K_{\mathrm{DP}}$. Examination of a significant sample of tropical and continental precipitation events indicated that $\alpha$ was sensitive to changes in drop size distribution and exhibited lower (higher) values when there were lower (higher) concentrations of larger (smaller) rain drops. As part of the performance assessment, the prototype algorithm generated QPEs utilizing a real-time estimated and a fixed $\alpha$ were created and evaluated. The results clearly indicated $\sim 26 \%$ lower errors and a $26 \%$ better bias ratio with the QPE utilizing a real-time estimated $\alpha$ as opposed to using a fixed value as was done in previous studies. Comparisons between the QPE utilizing a real-time estimated $\alpha$ and the operational dual-polarization (dual-pol) QPE used on the WSR-88D radar network showed the former exhibited $\sim 22 \%$ lower errors, $7 \%$ less bias, and $5 \%$ higher correlation coefficient when compared to quality controlled gauge totals. The new QPE also provided much better estimates for moderate to heavy precipitation events and performed better in regions of partial beam blockage than the operational dual-pol QPE.
\end{abstract}

\section{Introduction}

A number of studies have examined the use of specific attenuation $A$ to estimate rainfall. Ryzhkov et al. (2014) examined the feasibility of utilizing $A$ for estimating rainfall rain rates $R(A)$. Their study developed the methodology to estimate rainfall via $A$ for $\mathrm{X}$-, C- and S-band radars and used the ZPHI method (Bringi et al. 1990; Testud et al. 2000; Bringi et al. 2001) for estimating

Corresponding author: Stephen B. Cocks, stephen.cocks@ noaa.gov the $A$ fields. Key to this technique was the estimation of the path integrated attenuation, which is related to the product of the span of differential phase, and the parameter $\alpha$ defined as the ratio of $A$ to specific differential phase $K_{\mathrm{DP}}$, along a radar radial [their Eq. (1)]. Using a small sample of cases, Ryzhkov et al. (2014) showed that the parameter $\alpha$ could vary in different rainfall regimes. To generate $R(A)$ estimates, they assumed a fixed $\alpha$ that was representative of the rainfall regime type present (continental or tropical). Their $R(A)$ comparisons with gauges for a small sample of cases indicated the potential for significant improvement utilizing this technique. 
Giangrande et al. (2014) and Boodoo et al. (2015) explored $R(A)$ applications for C-band radars while Diederich et al. (2015) explored applications for X-band radars. In all of these studies, the parameter $\alpha$ was assumed to be insensitive to the drop size distribution (DSD) variability for a given case.

The first paper of this series (Wang et al. 2019, hereafter Part I) provides the description of an operational prototype quantitative precipitation estimate (QPE) algorithm for S-band radars utilizing specific attenuation $A$ that is an extension of the technique developed by Ryzhkov et al. (2014). The paper demonstrates that the parameter $\alpha$ can exhibit significant variability within tropical and continental rainfall events. This motivated the development of a technique to estimate the net $\alpha$ for the radar field of view (FOV) via the slope of the $Z_{\mathrm{DR}}$ dependence on $Z$ for each $0.5^{\circ}$ tilt. Because $A$ cannot be reliably estimated in mixed-phase or frozen precipitation, Part I used rain rates estimated via specific differential phase $K_{\mathrm{DP}}$ in regions where hail was likely (reflectivity $Z>50 \mathrm{~dB} Z$ ). Further, they used model sounding data to diagnose the height of the melting layer to mitigate any QPE impacts caused by melting hydrometeors.

This paper, the second of the series, assesses the performance of the prototype QPE algorithm using S-band radar data collected from a large number of warm season precipitation events. It will further refine the typical values of $\alpha$ for a significant number of tropical and continental rainfall events. Using the prototype $R(A)$ algorithm developed in Part I, QPEs generated using a fixed $\alpha$ and a real-time estimated $\alpha$ are compared to quality controlled gauge data to determine which produces the more accurate rainfall estimates. The $R(A)$ QPEs performance will then be compared to that of the operational dual-polarization (dual-pol) QPE algorithm which utilizes $R\left(Z, Z_{\mathrm{DR}}\right)$ for pure rain and $R\left(K_{\mathrm{DP}}\right)$ for rain mixed with hail (Giangrande and Ryzhkov 2008; Berkowitz et al. 2013). The performance comparisons will utilize the software infrastructure and archived gauge data provided by the Multi-Radar Multi-Sensor (MRMS) system (Zhang et al. 2016). The MRMS platform is perfectly suited for a large-scale validation of new hydrometeorological algorithms as it allows for the quick and effective assessment of a large number of cases in a relatively short period of time.

The paper is organized as follows: section 2 outlines the validation methodology, and section 3 documents the median value of $\alpha$ for a significant sample of continental and tropical precipitation systems. Section 4 compared the performance of the two $R(A)$ QPE versions with that of the operational dual-pol QPE, and the summary and conclusions are included in section 5 .

\section{Data and methodology}

Next Generation Weather Radar (NEXRAD) level II data were collected from 51 precipitation events on 37 calendar days from 33 Weather Surveillance Radar1988 Doppler (WSR-88D) radars east of the Rocky Mountains as shown in Fig. 1. Nonmeteorological echoes were removed via a quality control algorithm that utilized dual-pol cross-correlation coefficient $\rho_{\mathrm{HV}}$ data and a set of heuristic rules (Tang et al. 2014). Radial profiles of specific attenuation were estimated from radial profiles of $Z$ and the total span of differential phase as determined by Eqs. (3)-(5) in Part I. Two $R(A)$ QPEs were generated utilizing the prototype $R(A)$ algorithm developed in Part I: one that used a fixed value of $\alpha\left[R(A)_{\text {fix_ } \alpha}\right]$ and one that utilized a real-time estimated $\alpha\left[R(A)_{\text {adj_ } \alpha}\right]$ for each $0.5^{\circ}$ tilt during the 24-h period evaluated. For the $R(A)_{\text {fix } \_\alpha}$ QPE, $\alpha$ was set equal to $0.015 \mathrm{~dB}$ per degree, the value typically used for continental rainfall which is common across the contiguous United States. Rain rates were calculated using the $R(A)$ and $R\left(K_{\mathrm{DP}}\right)$ power laws given by Eqs. (9) and (11) in Part I for $Z \leq 50 \mathrm{~dB} Z$ and $Z>50 \mathrm{~dB} Z$, respectively.

Point-to-point comparisons of $R(A)$ QPE with 24-h and hourly gauge totals were used to assess its performance. A number of factors were taken into account for this type of assessment: radar-derived precipitation estimates may be impacted by ground clutter, blockage, nonmeteorological echoes, increased sample volumes at greater distances, beam overshoot, bright band effects, improper calibration, and the use of improper reflectivity-to-rain rate $R(Z)$ relationships (Steiner et al. 1999; Zhang et al. 2012; Smith et al. 1996; Zhang and Qi 2010; Krajewski et al. 2010; Droegemeier et al. 2000). Gauge totals may be biased by orifice blockages, poor site placement, undercatch due to wind, power outages preventing data transmission, mechanical malfunctions, telemetry and transmission problems (Sieck et al. 2007; Fiebrich et al. 2010; Wilson and Brandes 1979; Martinaitis 2008; Groisman and Legates 1994; Kim et al. 2009). Hence, precipitation estimates were validated against a combination of quality controlled Community Collaborative Rain, Hail and Snow Network (CoCoRaHS; Reges et al. 2016) and Hydrometeorological Automated Data System (HADS) rain gauges. Statistical measures used in the evaluations were mean bias ratio, defined as the ratio of the QPE estimate to the gauge total, rootmean-square error (RMSE), mean absolute error (MAE), and correlation coefficient. 


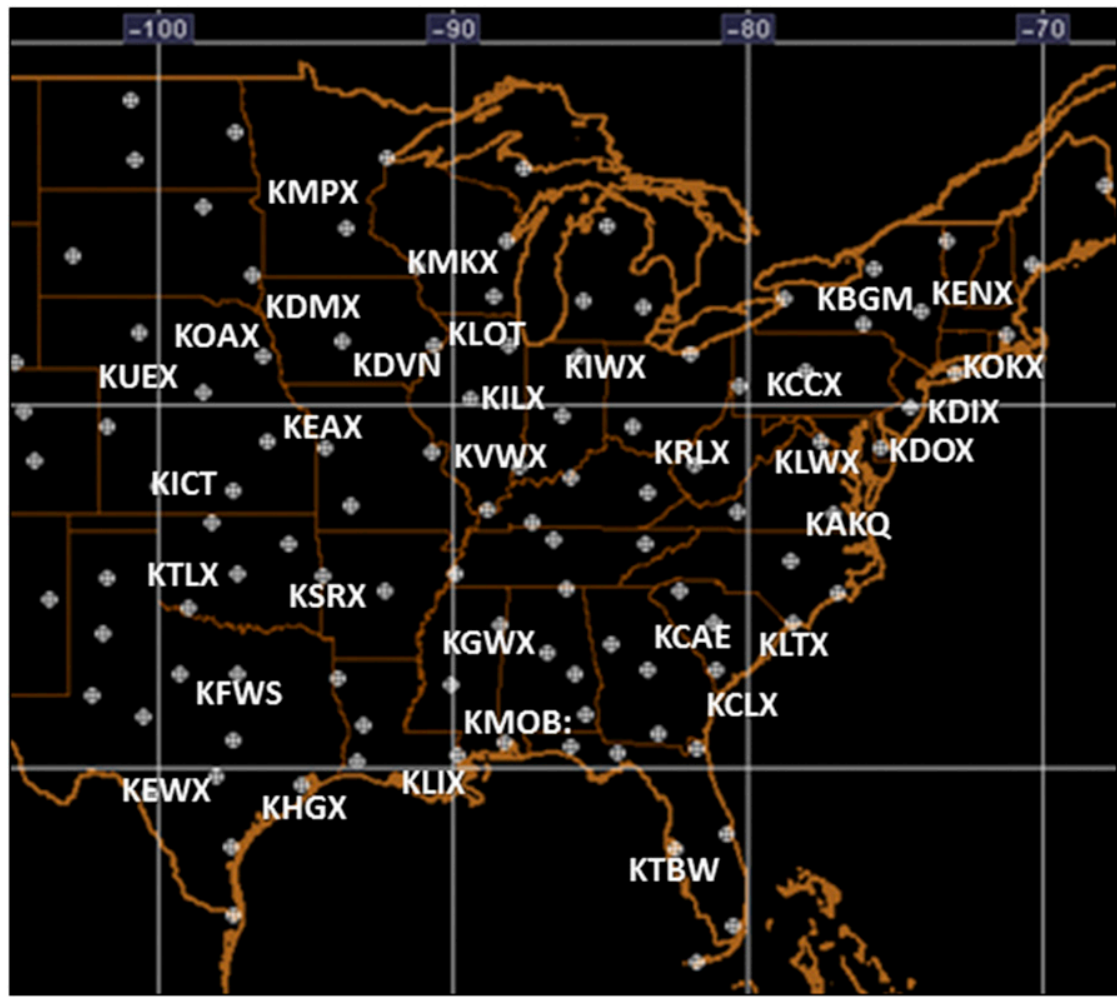

FIG. 1. Names and locations of radars used within the study.

\section{Median $\alpha$ for tropical and continental precipitation systems}

A key for accurate estimation of specific attenuation $A$ along the radial is the optimal choice of the parameter $\alpha$, defined as the net ratio of $A$ to $K_{\mathrm{DP}}$ along the propagation path, as part of the path-integrated attenuation (PIA) calculation as discussed by Ryzhkov et al. (2014). Ryzhkov et al. (2014) noted that $A$ is directly proportional to $\alpha$, hence, obtaining a good estimate of $\alpha$ is of critical importance for good-quality rainfall estimates from the $R(A)$ relation. Both Ryzhkov et al. (2014) and Part I noted that the parameter $\alpha$ is generally quite different in continental and tropical precipitation systems.

In our study, we use a large sample of tropical and continental precipitation events to determine the median $\alpha$ values for the two rain types. Using $0.5^{\circ}$ tilts where significant radar echoes were present, the median $\alpha$ was calculated using 9 days of tropical (5115 tilts) and 13 days of continental (5733 tilts) precipitation events listed in Tables 1 and 2. The criteria used to distinguish between tropical and continental precipitation events were the following: 1) tropical events were associated with tropical cyclones and/or slow moving upper-level troughs that occurred over or near the coastline (see Table 1) and 2) continental events were generally mesoscale convective systems (MCSs) associated with more progressive upper level troughs/jets, significant numbers of severe weather reports and, in all but one case, occurred well away from the coastline (see Table 2). Our statistical analysis indicates that the median $\alpha$ for continental events was $0.018 \mathrm{~dB}$ per degree while for tropical events median $\alpha$ was $0.028 \mathrm{~dB}$ per degree. The median tropical $\alpha$ obtained for tropical events was quite similar to that reported by Ryzhkov et al. (2014) $(0.030 \mathrm{~dB}$ per degree $)$. The median continental $\alpha$ was a little higher than the aforementioned study likely because the prototype algorithm in Part I does not allow $\alpha<0.015 \mathrm{~dB}$ per degree. The underlying reason for the difference in $\alpha$ between the two rain types is that in tropical rain, $A$ is high but $K_{\mathrm{DP}}$ is low due to the abundance of small drops having a nearly spherical shape resulting in a higher $A / K_{\mathrm{DP}}$ ratio as opposed to the continental rain commonly dominated by large nonspherical drops originating from melting graupel and hail.

Apart from the general difference in the magnitude of $\alpha$ in tropical and continental rain, Part I demonstrated significant $\alpha$ variability during both tropical and continental precipitation events. This dictated the need to update the optimal value of the factor $\alpha$ on a scan-to-scan basis and motivated Wang et al. in Part I to develop a technique to estimate the net $\alpha$ for the whole radar field of view (FOV) using a slope of the $Z_{\mathrm{DR}}$ dependence on $Z$ in rain at the 
TABLE 1. Event description, 24-h accumulation period, radar name, and the approximate number of severe weather reports within the radar FOV for the precipitation events used to determine the median value of $\alpha$ for tropical rainfall. "Few" represented $<4$, "some" $\leq 10$, and "numerous" >10 severe weather reports; TS and TD refer to tropical storm and tropical depression, respectively.

\begin{tabular}{|c|c|c|c|}
\hline Event type & $\begin{array}{l}\text { Date of 24-h period } \\
\text { ending 0700 LST }\end{array}$ & Radar(s) & Severe reports \\
\hline TS Bill & 17 Jun 2015 & KHGX, KFWS & Few \\
\hline TD Bill & 18 Jun 2015 & KFWS & None \\
\hline $\begin{array}{l}\text { Rain associated with Hurricane Joaquin and quasi-stationary } \\
\text { upper low }\end{array}$ & 2 Oct 2015 & KCAE & None \\
\hline $\begin{array}{l}\text { Rain associated with Hurricane Joaquin and quasi-stationary } \\
\text { upper low }\end{array}$ & 3 Oct 2015 & KCAE & None \\
\hline $\begin{array}{l}\text { Rain associated with Hurricane Joaquin and quasi-stationary } \\
\text { upper low }\end{array}$ & 4 Oct 2015 & KCAE, KLTX & Few \\
\hline TS Colin & 7 Jun 2016 & KTBW & Few \\
\hline Rain associated with westward moving tropical wave & 12 Aug 2016 & KLIX & None \\
\hline Rain associated with westward moving tropical wave & 13 Aug 2016 & KLIX & None \\
\hline Hurricane Matthew & 8 Oct 2016 & KCLX & Few \\
\hline
\end{tabular}

$0.5^{\circ}$ antenna tilt. The results of this section further confirm the need to use a real-time adjusted $\alpha$ to improve $R(A)$ QPE rather than using a fixed $\alpha$ for the entire precipitation event. The next section validates this finding by comparing $R(A)$ estimates utilizing a fixed $\alpha\left[R(A)_{\text {fix } \_\alpha}\right]$ with those utilizing a real-time adjusted $\alpha\left[R(A)_{\text {adj_}} \alpha\right]$. In turn, the performance of the $R(A)$-based QPEs algorithm will be compared to that of the operational dual-pol QPE which primarily uses the $R\left(Z, Z_{\mathrm{DR}}\right)$ relation in pure rain and $R\left(K_{\mathrm{DP}}\right)$ in regions where hail was likely.

\section{Prototype QPE algorithm performance assessment and case study analysis}

a. Performance Assessment of the $R(A)_{a d j \_}, R(A)_{f i x \_\alpha \text {, }}$ and operational dual-pol QPE algorithms

To assess the impact of the variability of $\alpha$ on the performance of the attenuation-based rainfall estimation, we evaluated two versions of the $R(A)$ algorithm: one version that generated QPE derived from $\alpha$ estimated and updated for each $0.5^{\circ}$ tilt $\left[R(A)_{\text {adj } \_\alpha}\right]$ for the radar FOV and one that generates QPE assuming a fixed value of $\alpha\left[R(A)_{\text {fix } \_\alpha}\right]$ for the entirety of the event. The $\alpha$ value set for the $R(A)_{\text {fix } \_\alpha}$ QPE was $0.015 \mathrm{~dB}$ per degree, the typical value recommended by Ryzhkov et al. (2014) for continental precipitation systems. For both of these $R(A)$ QPEs, we substituted $R(A)$ with $R\left(K_{\mathrm{DP}}\right)$ whenever $Z>$ $50 \mathrm{~dB} Z$ to mitigate the risk of contamination by hail. These two QPEs are compared to the operational dual-pol QPE rain totals and performance statistics are generated. All QPE data were compared to quality controlled 24-h totals from CoCoRaHS and HADS gauge data from 49 precipitation events east of the Rockies during the 2014-16 warm seasons.

Figures $2 \mathrm{a}-\mathrm{c}$ show the resulting scatterplots and the statistical measures. Nonparametric bootstrap significance

TABLE 2. Event description, 24-h accumulation period, radar name, and the approximate number of severe weather reports within the radar FOV for the precipitation events used to determine the median value of $\alpha$ for continental rainfall. "Few" represented $<4$, "some" $\leq 10$, and "numerous" $>10$ severe weather reports.

\begin{tabular}{lclc}
\hline \hline \multicolumn{1}{c}{ Event type } & $\begin{array}{c}\text { Date of 24-h period } \\
\text { ending 0700 LST }\end{array}$ & \multicolumn{1}{c}{ Radar(s) } & \multicolumn{1}{c}{ Severe reports } \\
\hline MCS & 29 Apr 2014 & KMOB & Some \\
MCS & 13 May 2014 & KFWS & Nome \\
Initially supercells then MCS & 4 Jun 2014 & KOAX & KMPX, KDMX \\
MCSs & 20 Jun 2014 & KOAX & Few \\
MCSs & 5 Jul 2014 & KILX & Some \\
MCS & 13 Jul 2014 & KTLX & Some \\
Initially rain, then MCS & 6 May 2015 & KTLX & Few \\
Early rain/afternoon supercells & 7 May 2015 & KILX & Few \\
Decaying MCS then afternoon storms consolidating to MCS & 8 Jun 2015 & KDVN & FGWX \\
Morning rain; afternoon storms & 12 Jun 2015 & Kul 2015 & KLOT, KEAX \\
MCSs & 7 Jul 2015 & KRLX & Some \\
Afternoon line of storms & 24 Jun 2016 & & Numerous \\
Numerous severe storms & & &
\end{tabular}



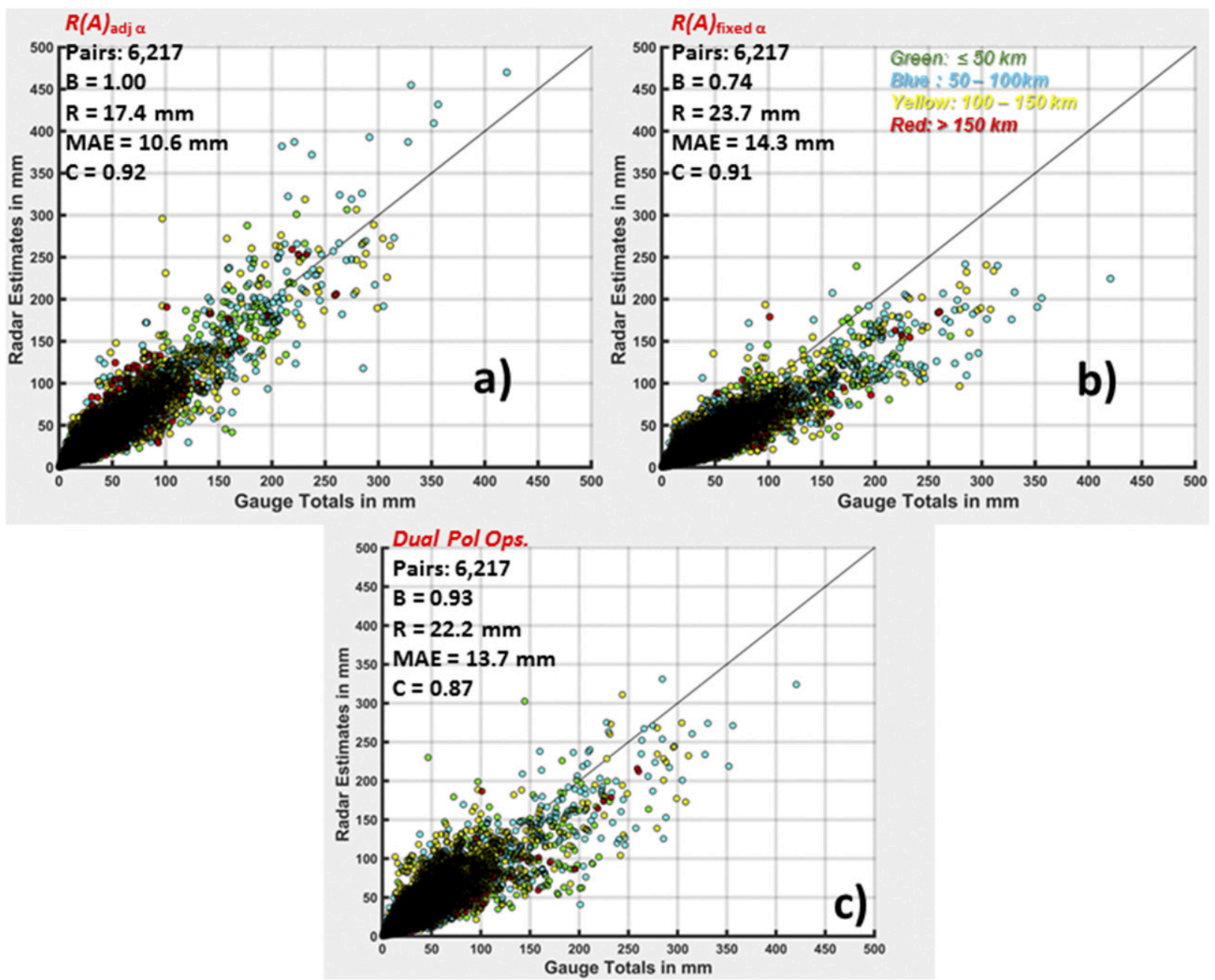

FIG. 2. (a) The 24-h accumulations of $R(A)_{\text {adj } \_}$, (b) $R(A)_{\text {fix } \alpha}$ utilizing a fixed $\alpha$ value of 0.015 , and (c) the operational dual-pol QPE as compared to quality controlled gauge data for 49 cases used in the performance evaluation. The letters B, R, MAE, and $\mathrm{C}$ stand for radar-to-gauge bias ratio, RMSE, MAE, and correlation coefficient, respectively.

tests (Efron and Tishirani 1993) were conducted for the differences in RMSE, MAE, and correlation coefficient between the three QPE and all were found to be statistically significant to the $95 \%$ confidence level. That is, the $95 \%$ confidence interval of the difference of a given statistic for the QPE pair being evaluated does not contain the value zero. A comparison of the $R(A)_{\text {adj } \alpha} \alpha$ (Fig. 2a) performance with that of $R(A)_{\text {fix } \_\alpha}$ (Fig. 2b) in terms of 24-h totals shows significant differences in error and in the radar-to-gauge bias. The latter exhibited significantly higher ( $26 \%)$ RMSE and MAE errors and a $26 \%$ larger underestimate bias ratio. Comparisons of the $R(A)_{\text {adj_ } \alpha}$ estimates with the operational dual-pol QPE (Fig. 2c) also show significantly lower $(\sim 22 \%)$ RMSE/MAE errors, higher $(\sim 5 \%)$ correlation coefficient and $7 \%$ better radar-to-gauge bias ratio for the former. Similar to the scatterplots, the QPE errors as a function of distance (not shown) indicated that $R(A)_{\text {adj_ } \alpha}$ exhibited much less variability and bias than $R(A)_{\text {fix } \_\alpha}$ and the operational dual-pol.

The scatterplots also indicate $R(A)_{\text {adj_ } \alpha}$ QPE does a much better job estimating rainfall for gauge totals $>150 \mathrm{~mm}$, that is, the moderate-to-heavy rain events that produce the most risk for significant flooding. This is more clearly indicated when viewing a normalized hit/miss contingency table (Wilks 2006). The 24-h QPE and gauge totals were divided into five categories: very light (totals $T<12.7 \mathrm{~mm})$, light $(12.7 \leq T<38.1 \mathrm{~mm})$, moderate $(38.1 \leq T<101.6 \mathrm{~mm})$, heavy $(101.6 \leq T<$ $152.4 \mathrm{~mm})$, and extreme $(T \geq 152.6 \mathrm{~mm})$. If the QPE category matched the gauge category data, then the QPE was considered to have made a good estimate and was classified as a "hit," otherwise it was classified as a "miss." Table 3 showed a summary of the analysis with 
TABLE 3. Column normalized hit/miss matrices for 24-h $R(A)_{\text {adj } \_\alpha}$, $R(A)_{\text {fix } \_\alpha}$, and dual-pol QPE totals (in rows) vs observed 24-h gauge totals (in columns). Precipitation categories shown were for very light (VL), light (L), moderate (M), heavy (H), and extreme (E) 24-h gauge totals. Values along the diagonal (bold font) meant the QPE category matched the gauge category and were considered hits. Values off the diagonal (italic font) were considered misses and indicated the types of misclassifications made.

\begin{tabular}{clccccc}
\hline \hline QPE product & & $\mathrm{VL}$ & $\mathrm{L}$ & $\mathrm{M}$ & $\mathrm{H}$ & $\mathrm{E}$ \\
\hline$R(A)_{\text {adj_ } \alpha}$ & VL & $\mathbf{0 . 7 9}$ & 0.09 & & & \\
& $\mathrm{~L}$ & 0.21 & $\mathbf{0 . 7 4}$ & 0.18 & & \\
& $\mathrm{M}$ & & 0.16 & $\mathbf{0 . 7 7}$ & 0.45 & 0.03 \\
& $\mathrm{H}$ & & & 0.05 & $\mathbf{0 . 4 8}$ & 0.19 \\
& $\mathrm{E}$ & & & & 0.07 & $\mathbf{0 . 7 8}$ \\
$R(A)_{\text {fix } \_\alpha}$ & $\mathrm{VL}$ & $\mathbf{0 . 9 0}$ & 0.25 & 0.01 & & \\
& $\mathrm{~L}$ & 0.10 & $\mathbf{0 . 6 9}$ & 0.41 & 0.02 & \\
& $\mathrm{M}$ & & 0.06 & $\mathbf{0 . 5 7}$ & 0.87 & 0.16 \\
& $\mathrm{H}$ & & & 0.01 & $\mathbf{0 . 1 1}$ & 0.48 \\
& $\mathrm{E}$ & & & & & $\mathbf{0 . 3 6}$ \\
Dual-pol & $\mathrm{VL}$ & $\mathbf{0 . 8 3}$ & 0.14 & & & \\
& $\mathrm{~L}$ & 0.17 & $\mathbf{0 . 6 8}$ & 0.23 & 0.01 & \\
& $\mathrm{M}$ & & 0.18 & $\mathbf{0 . 7 1}$ & 0.59 & 0.20 \\
& $\mathrm{H}$ & & & 0.05 & $\mathbf{0 . 3 8}$ & 0.31 \\
& $\mathrm{E}$ & & & & 0.02 & $\mathbf{0 . 4 9}$ \\
\hline
\end{tabular}

the QPE categories shown in the rows and the observed gauge totals shown in the columns. The data in each column were normalized by the total number of radarto-gauge $(\mathrm{R} / \mathrm{G})$ pairs within that category such that it added up to 1 or, due to round off error, 0.99. The bold font numbers represent the ratio of hits to all possible $\mathrm{R} / \mathrm{G}$ pairs for a category and placed along the diagonal of the three table blocks. The ratio of misses to all $\mathrm{R} / \mathrm{G}$ pairs for a given category is denoted by italicized numbers off the diagonal. Both dual-pol and $R(A)_{\text {fix } \_\alpha}$ had higher hit rates for the very light rain category. However, the data show the $R(A)_{\text {adj } \alpha}$ QPE does a significantly better job of matching the gauge category for light (0.74), moderate (0.77), heavy (0.48), and extreme (0.78) precipitation events than both $R(A)_{\text {fix } \_\alpha}$ and operational dual-pol QPEs. This is important as most flash floods are associated with moderate to extreme precipitation events. Further, the results confirm the importance of using a real time estimated $\alpha$ to get the most accurate $R(A)$ QPE possible. While both QPEs exhibited nearly the same hit rate for light precipitation, operational dual-pol outperformed $R(A)_{\text {fix }_{\alpha} \alpha}$ for the moderate, heavy, and extreme categories. With regard to the QPE performance in very light rain, an analysis (not shown) of $R(A)_{\text {adj_ } \alpha}$ and dual-pol indicated both QPEs exhibited an overestimate bias similar to that found in Cocks et al. (2017). From that study, four QPEs were examined and each exhibited an overestimate bias ratio in the very light precipitation category likely due to impacts caused by evaporation of smaller rain drops. The use of a lower $\alpha(0.015)$ at all times, which significantly lowered rain rates, is likely the reason for the better $R(A)_{\text {fix } \_\alpha}$ performance in the VL category.

Figures $3 \mathrm{a}$ and $3 \mathrm{~b}$ show scatterplots of hourly accumulations estimated from $R(A)_{\text {adj_ } \alpha}$ and operational dual-pol algorithms versus quality controlled automated gauge data using a subset of 20 rain events. Although the results are more subtle due to the smaller accumulation time and the enhanced variability typically found in hourly accumulations, the scatterplots show the $R(A)_{\text {adj_ } \alpha}$ QPE exhibited significantly less variability and performed better for gauge totals $>40 \mathrm{~mm}$. Nonparametric bootstrap statistical tests also indicated the differences in RMSE, MAE, and correlation coefficient are significant with higher correlation/lower error associated with the $R(A)_{\text {adj_ } \alpha}$ QPE.

\section{b. $R(A)_{a d j \_\alpha} Q P E$ performance during a severe convective storm event}

On 3 and 4 June 2014 severe storms occurred over eastern Nebraska and western Iowa. Associated with this convective event were numerous severe hail and wind reports within the Omaha, Nebraska (KOAX), WSR-88D radar's FOV. In some cases, hail likely impacted gauge performance, due to the clogging of gauge orifices by smaller hailstones, or by possibly damaging the gauge site itself as hail $>75 \mathrm{~mm}$ was reported with this event. The former effect was detectable as a few gauges continued to report low precipitation totals for three or more hours after rainfall ended, an effect typically observed during the winter season a day or two after a winter storm when clear skies prevail (Martinaitis et al. 2015). These effects were mitigated by removing any gauges missing hourly reports, exhibiting erratic performance over the 24 -h period and by comparing hourly and 24 -h gauge totals with available nearby gauges.

While strong sustained winds did not last for as long of a period as that typically observed in hurricanes, there were quite a number of peak wind gust measurements $>35.8 \mathrm{~m} \mathrm{~s}^{-1}$. There were also a number of stations that reported heavy rainfall during the event. Hence, gauge undercatch, due to turbulent wind flow over the gauge orifice and, for tipping-bucket gauges, due to the time required for the bucket to tip from one side to the other, likely impacted gauge totals. Duchon and Biddle (2010) and Duchon et al. $(2014,2017)$ noted that significant gauge undercatch occurred for wind speeds $\geq 5 \mathrm{~m} \mathrm{~s}^{-1}$ and, for tipping-bucket gauges, rain rates $>50 \mathrm{~mm}$. Comparing gauge accumulations above ground and within a pit, Sieck et al. (2007) found gauge undercatch ranged from $2 \%$ to $10 \%$ for the precipitation 

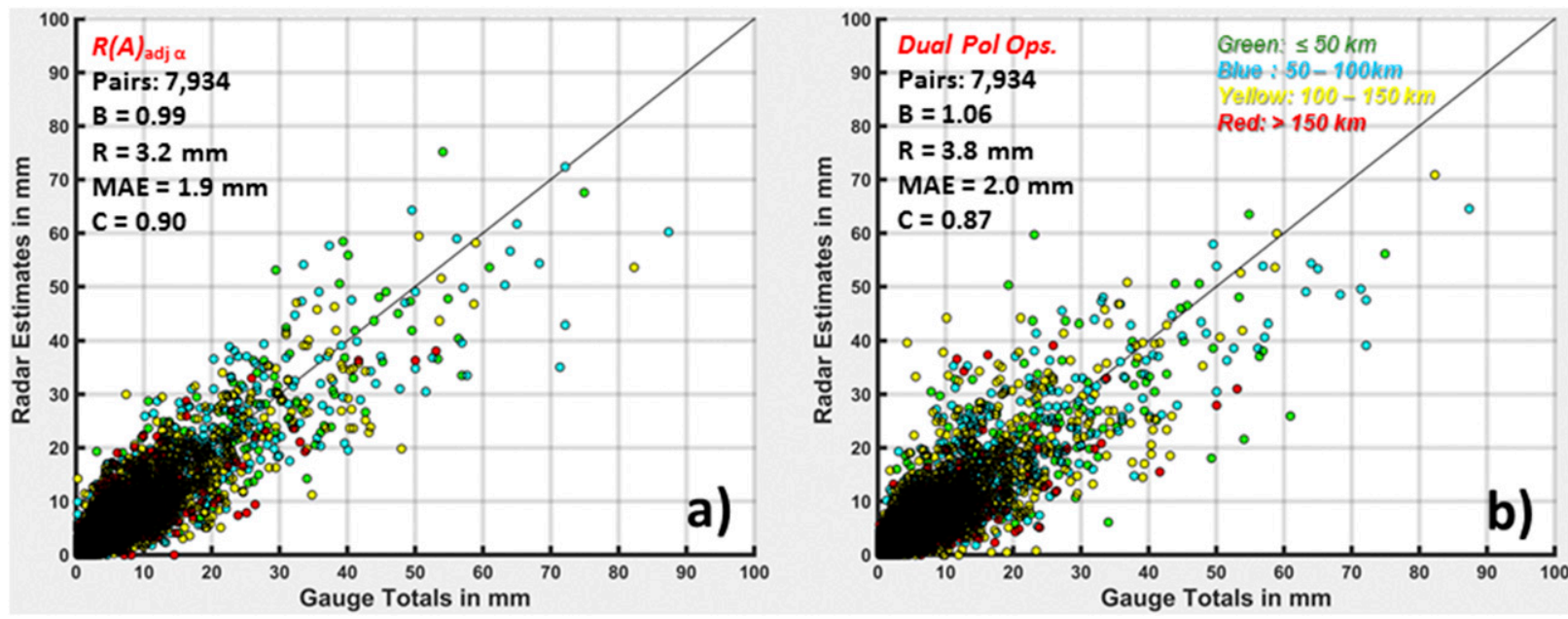

FIG. 3. (a) The 1-h accumulations of $R(A)_{\text {adj } \alpha}$ and (b) the operational dual-pol QPE compared to quality controlled gauge data for 20 of the 49 cases used in the performance evaluation. The legend is the same as in Fig. 2.

events accompanied by winds of generally $\leq 6 \mathrm{~m} \mathrm{~s}^{-1}$. However, Duchon and Essenberg (2001) noted that for one rainfall event they measured gauge undercatch of $12 \%-15 \%$ during a period where winds were $12.5 \mathrm{~m} \mathrm{~s}^{-1}$ and the rain rate was $200 \mathrm{~mm} \mathrm{~h}^{-1}$.

We examined time series of the hourly median $R(A)_{\text {adj } \_\alpha}$ and dual-pol QPE errors using quality controlled automated gauges within $120 \mathrm{~km}$. Further, due to the number of high wind reports during this precipitation event, it is of interest to examine median hourly QPE errors calculated using not only the reported gauge totals but also using gauge totals adjusted for undercatch due to strong winds. During this convective event, strong winds were sporadically present with the gauge undercatch likely between $5 \%$ and $10 \%$. As a simplification, a gauge undercatch of $10 \%$ was assumed for all the hourly gauges used in the time series as this would potentially lower and increase the dual-pol and $R(A)_{\mathrm{adj} \_\alpha}$ errors, respectively. That is, $10 \%$ was added to the gauge totals which in turn were compared to the QPE for each hour. The authors fully recognize that some gauges could have experienced a higher (particularly near intense convective cores) or a lower percentage of wind undercatch. However, this exercise provides an idea of the impacts the wind undercatch could have on QPE errors. The QPE errors, with (dashed line) and without (solid line) wind undercatch taken into account, are shown in Fig. 4 for the period between 2200 and 0900 UTC. It is clear that the median QPE error each hour, regardless of gauge undercatch, is lower for $R(A)_{\text {adj } \alpha \text {. Figure } 5 \text { illustrates }}$ the $R(A)_{\text {adj } \alpha}$ and dual-pol QPEs performance when compared to 24-h gauge totals for this event. Both Figs. 4 and 5 show that dual-pol QPE exhibits a significant overestimate bias ratio and higher errors than the $R(A)_{\text {adj_ } \alpha}$ QPE. While KOAX $Z_{\mathrm{DR}}$ appeared to be fairly well calibrated, $Z$ on average was 1.0 $1.5 \mathrm{~dB} Z$ higher than neighboring radars. Such positive bias might be partially contributing to the rainfall overestimation by the dual-pol algorithm which utilizes the $R\left(Z, Z_{\mathrm{DR}}\right)$ and $R(Z)$ rain rate relations. It is important that miscalibration of $Z$ and $Z_{\mathrm{DR}}$ does not affect the $R(A)_{\text {adj_} \_}$QPE performance. Overall, the new $R(A)_{\text {adj_} \_} \alpha$ QPE algorithm did very well during this event on both an hourly and 24-hourly time scale.

\section{c. $R(A)_{a d j \_\alpha}$ performance during Hurricane Matthew}

While the peak winds during Hurricane Matthew were somewhat comparable to the severe convective storm case previously evaluated, sustained wind speeds were higher for much longer periods of time over a wider area within the Charleston, South Carolina (KCLX), radar FOV. Hence, gauge undercatch due to strong winds was more widespread and very likely higher than in the severe convective storm case in Nebraska. Hourly wind observations, as shown in Figs. 6a-c, confirmed the presence of strong winds across much of the KCLX radar FOV during the evening and morning hours of 7 and 8 October. Figure $6 \mathrm{~d}$ shows a time series of the cumulative gauge and $R(A)$ QPE totals as well as sustained wind and hourly peak gust, measured by the Savannah, Georgia (KSAV), Automated Surface Observation System (ASOS) near the Georgia coast. Time series indicate that sustained winds (wind gusts) of $\sim 11-17 \mathrm{~m} \mathrm{~s}^{-1}\left(15-28 \mathrm{~m} \mathrm{~s}^{-1}\right)$ coincided with moderate to heavy rainfall between 2100 and 0800 UTC. During this period, the difference between the $R(A)_{\text {adj_ } \alpha}$ QPE estimate and the KSAV gauge total 


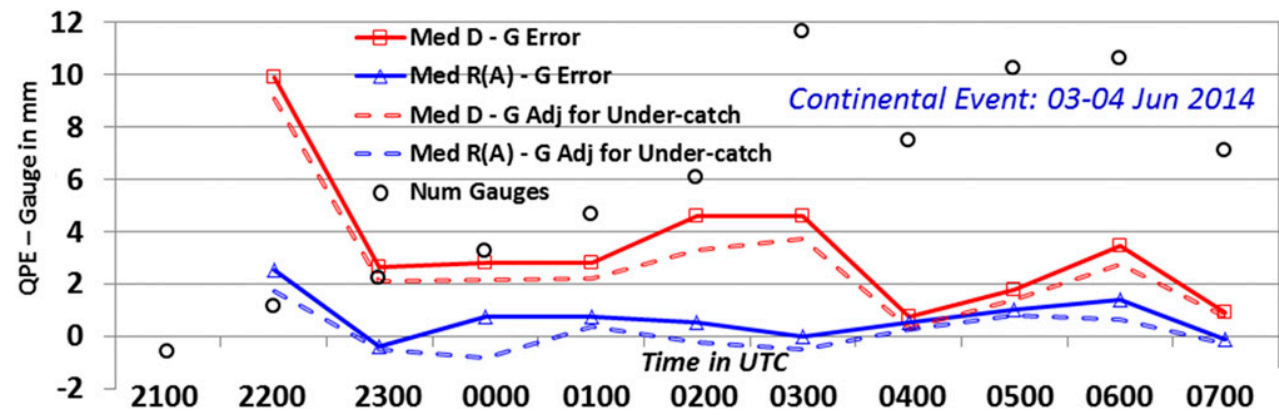

40

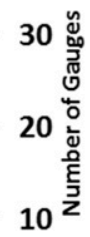

FIG. 4. Time series of hourly QPE - gauge errors during a continental precipitation event occurring within the KOAX FOV on 3 and 4 Jun 2014. Red (blue) lines represent dual-pol $\left[R(A)_{\text {adj_ } \alpha}\right]$ errors without (solid) and with $10 \%$ (dashed) gauge undercatch simulated (see legend annotated on the graph).

increased significantly. While there were also other factors impacting $R(A)_{\text {adj_ } \alpha}$ errors, gauge undercatch was a prominent factor that should be taken into account.

In a manner similar to what was done previously, a time series of QPE errors with 10\% (dashed line), $15 \%$ (dotted line), and without (solid line) wind undercatch taken into account are shown in Fig. 7 for the period between 1800 UTC 7 October and 1200 UTC 8 October. The $R(A)_{\text {adj_ } \alpha}$ QPE exhibited significant overestimates, particularly between 0200 and 0900 UTC, while dual-pol exhibited significant underestimates during the same period. The overall median QPE error for the period is 1.52 and $-2.29 \mathrm{~mm}$ for $R(A)_{\text {adj_ } \alpha}$ and dual-pol, respectively. From Fig. 7, it is clear that if gauge totals were adjusted for a potential undercatch of $10 \%$ or $15 \%$ (dashed and dotted lines) then the dual-pol error would significantly increase while the $R(A)_{\text {adj_ } \alpha}$ error would decrease. This indicated that the $R(A)_{\text {adj_ } \alpha}$ QPE quite likely performed better at the hourly time scale than initially indicated using gauge totals that were not taking into account gauge undercatch.

Figures $8 \mathrm{a}-\mathrm{d}$ illustrate the $R(A)_{\text {adj_ } \alpha}$ and dual-pol performance for 24-h gauge total estimation with and without adjustments made for at least $10 \%$ percent gauge undercatch across the KCLX FOV. Similar to Fig. 6, $R(A)_{\text {adi_ } \alpha}$ QPE exhibits significantly lower ( $\sim 17 \%)$ RMSE and MAE errors than dual-pol for gauge totals not adjusted for undercatch (Figs. 8a,b). The overall RMSE and MAE for the $R(A)_{\mathrm{adj}_{-} \alpha} \mathrm{QPE}$ decrease while that of dual-pol increase when the 24-h gauge totals are adjusted for $10 \%$ undercatch (Figs. 8c,d). As expected, the largest $R(A)_{\mathrm{adj}_{-} \alpha} \mathrm{QPE}$ overestimates were for gauge totals $>225 \mathrm{~mm}$ and were generally along the coastline where winds were stronger and undercatch likely higher than $10 \%$. Overall, the analysis strongly suggested $R(A)_{\text {adj_ } \alpha} \mathrm{QPE}$ quite likely performed better if gauge undercatch is taken into account.

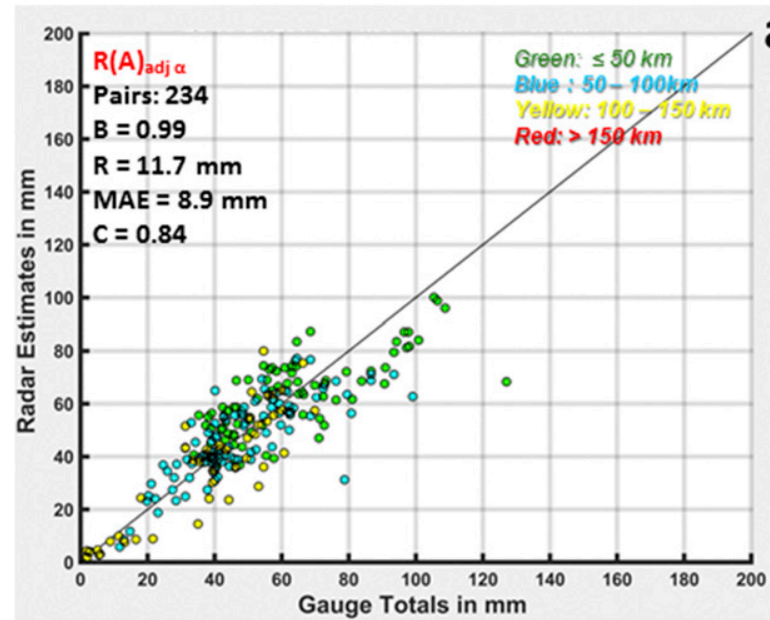

a)

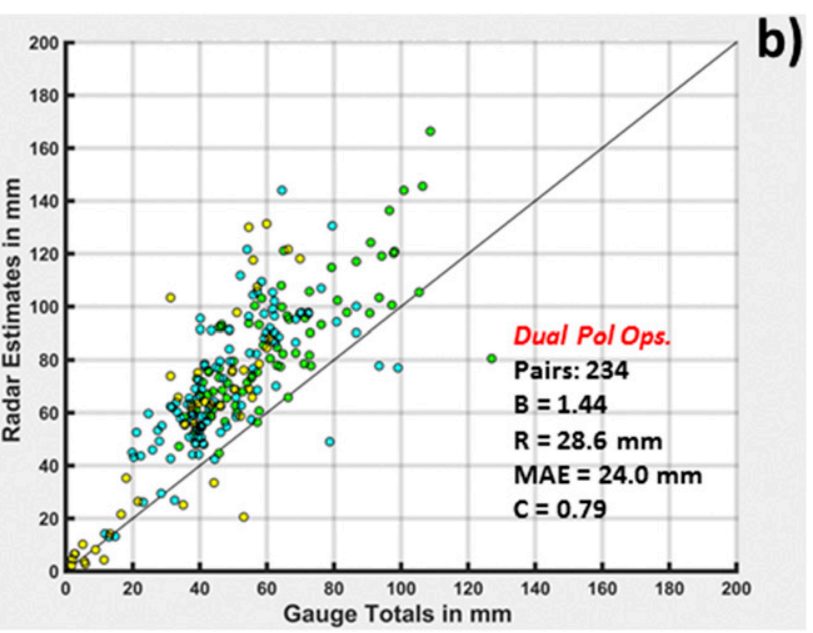

FIG. 5. (a) The $R(A)_{\text {adj } \_\alpha}$ and (b) operational dual-pol QPE as compared to quality controlled gauge totals using data from the KOAX radar for the 24-h period ending at 1200 UTC 4 Jun 2014. The legend is the same as in Fig. 2. 


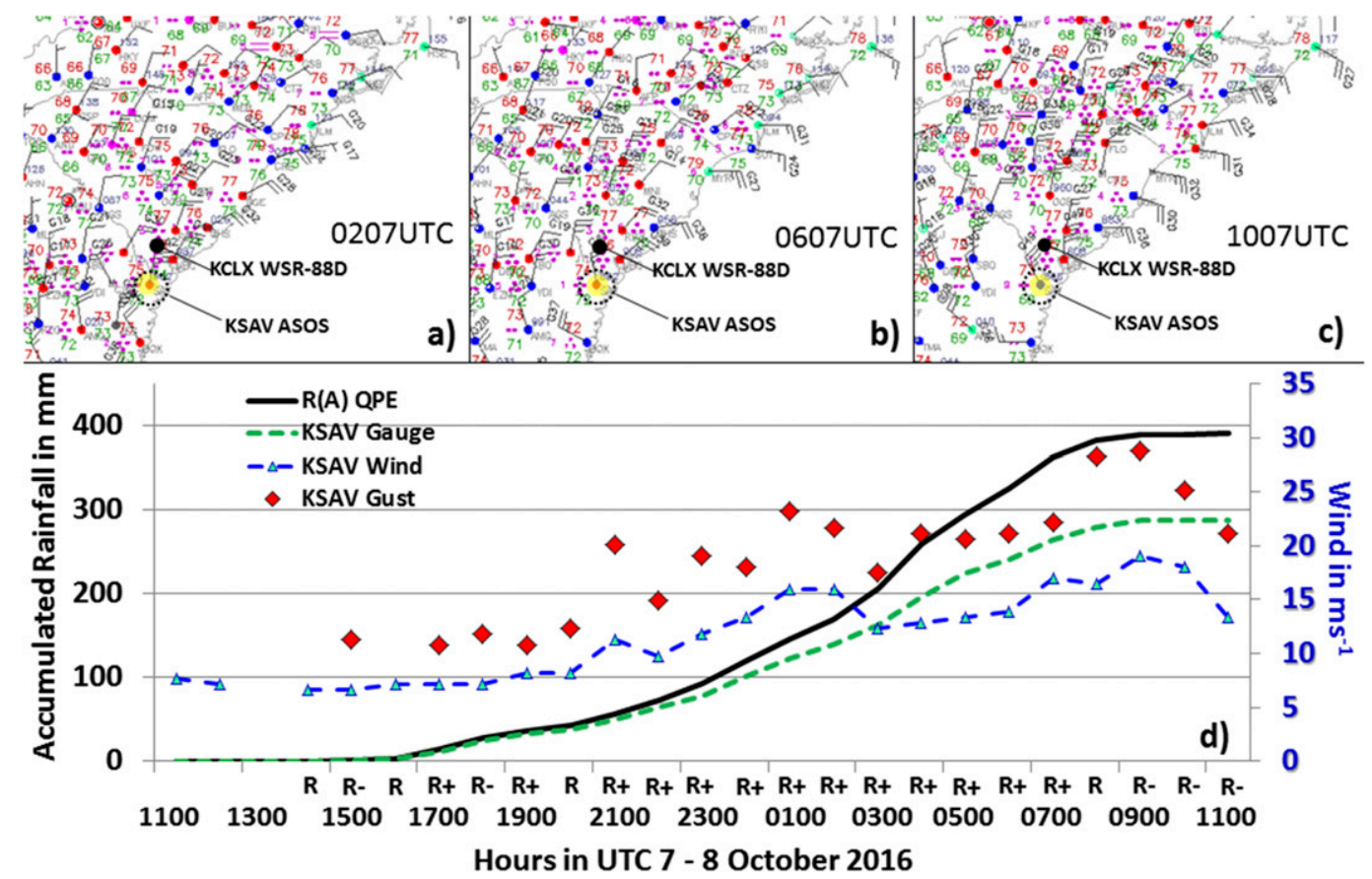

FIG. 6. Synoptic surface observations for (a) 0207, (b) 0607, and (c) 1007 UTC and (d) the 24-h time series of sustained wind/wind gusts, $R(A)_{\text {adj_ } \alpha}, \mathrm{QPE}$, and gauge cumulative totals for the KSAV ASOS site for 7 and 8 Oct 2016. The large black dot and black dashed circle with yellow shading in (a)-(c) denote the approximate location of the KCLX radar and KSAV ASOS location, respectively. For (d), R-, R, and R+ refer to light, moderate, and heavy rain, respectively, as reported by KSAV; the rest of the legend is provided on the image.

While there is an improvement for the larger $R(A)_{\text {adj_ } \alpha}$ QPE overestimates for 24-h gauge totals $>225 \mathrm{~mm}$, assuming a undercatch of $10 \%, 15 \%$, or even $20 \%$ (which is not shown), it is still not enough to account for the total overestimate bias, $\sim 30 \%$, observed along the coast. Instead, we believe that another (and probably more important) error source is the use of a single net $\alpha$ being applied indiscriminantly to the convective bands and stratiform rain areas of the storm. As discussed earlier, the $R(A)$ QPE generated with the prototype algorithm uses a net $\alpha$ derived from the $Z-Z_{\mathrm{DR}}$ pairs for the entire radar FOV below the melting layer. As explained in Part I, the use of a single net value of $\alpha$ in convective bands characterized by higher $Z$ and $Z_{\mathrm{DR}}$ and stratiform areas with lower $Z$ and $Z_{\mathrm{DR}}$ inevitably leads to overestimation of heavy rain and underestimation of lighter rain (see Fig. 2

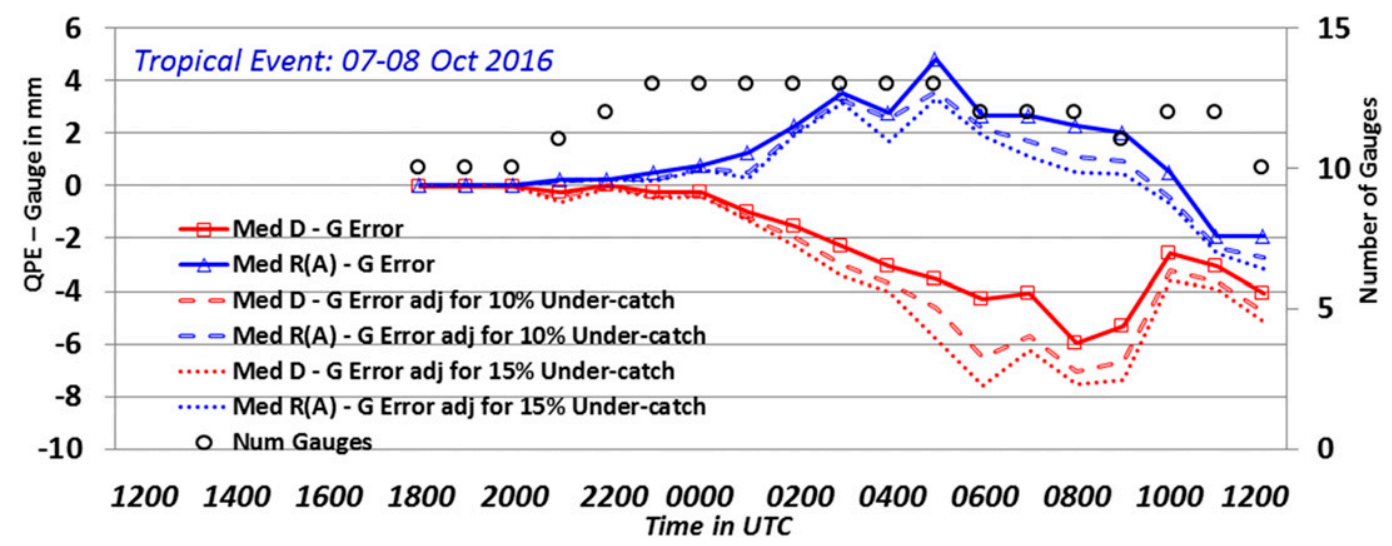

FIG. 7. Time series of hourly QPE - gauge errors during a tropical precipitation event occurring within the KCLX FOV on 7 and 8 Oct 2016. Red (blue) lines represent dual-pol $\left[R(A)_{\text {adj_ } \alpha}\right]$ errors without (solid) and with $10 \%$ (dashed) and 15\% (dotted) gauge undercatch simulated (see legend annotated on the graph). 

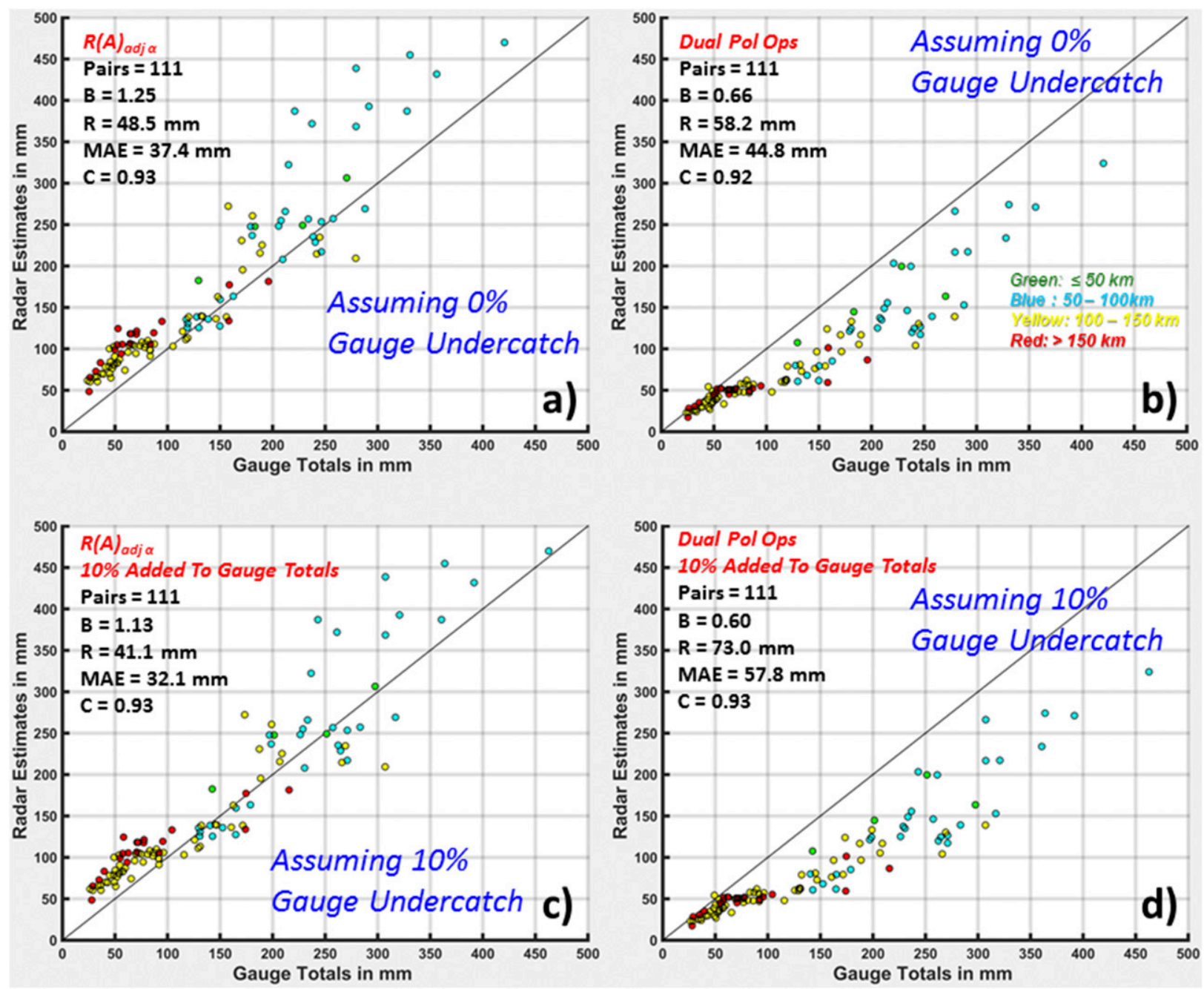

FIG. 8. (a),(c) Scatterplots of $R(A)_{\text {adj_ } \alpha}$ and (b),(d) dual-pol QPE vs (top) reported and (bottom) adjusted gauge totals for the 24-h period ending at 1100 UTC 8 Oct 2016. The adjusted gauge totals were created by adding $10 \%$ to the observed total to simulate gauge undercatch of $10 \%$ for the radar field of view. The legend is the same as in Fig. 2.

in Part I). This is also illustrated in a conceptual plot in Fig. 9. Across the coastal regions with stronger rainbands and eyewall convection, the "true" local value of $\alpha$ is likely lower than the net value $\alpha_{0}$ for the whole FOV and the use of $\alpha_{0}$ may result in rainfall overestimation there.

Another possible source of error is contamination from the melting layer. The $R(A)_{\text {adj_ } \alpha}$ QPE overestimates seen in Fig. 8a for gauge totals $<100 \mathrm{~mm}$ and associated with locations in an arc west-southwest through northnortheast of the radar at distances $>100 \mathrm{~km}$ might be caused by such contamination due to an improperly diagnosed melting layer. Figure 10a shows the location of these areas of overestimation (clustered in the shape of a crescent and indicated by blue bubbles) with respect to the radar. The accompanying digital hybrid scans of reflectivity $Z$ and cross-correlation coefficient $\rho_{\mathrm{hv}}$ are displayed in Figs. 10b-d for 0300 and 0600 UTC 8 October 2016. Model sounding data suggest specific attenuation based rain estimates can be made out to $190 \mathrm{~km}$ from the radar. Yet, the $\rho_{\mathrm{hv}}$ data clearly indicate that the area of melting layer contamination is significantly closer (at $150 \mathrm{~km}$ ) to the radar from approximately $240^{\circ}-360^{\circ}$ azimuth and antenna elevation $0.5^{\circ}$. Model reruns utilizing the lower melting layer bottom, indicated by the $\rho_{\mathrm{hv}}$ data, reduce errors by $11 \%$. Most of the overestimate bias bubbles (the cool colored circles in Fig. 10a) were located within or just below the melting layer as indicated by the $\rho_{\mathrm{hv}}$ data. Overall, contamination from the melting layer alone does not account for the entire overestimation errors observed; it is its combination with gauge undercatch and the use of an unrepresentative $\alpha$ in convective rainbands that might 


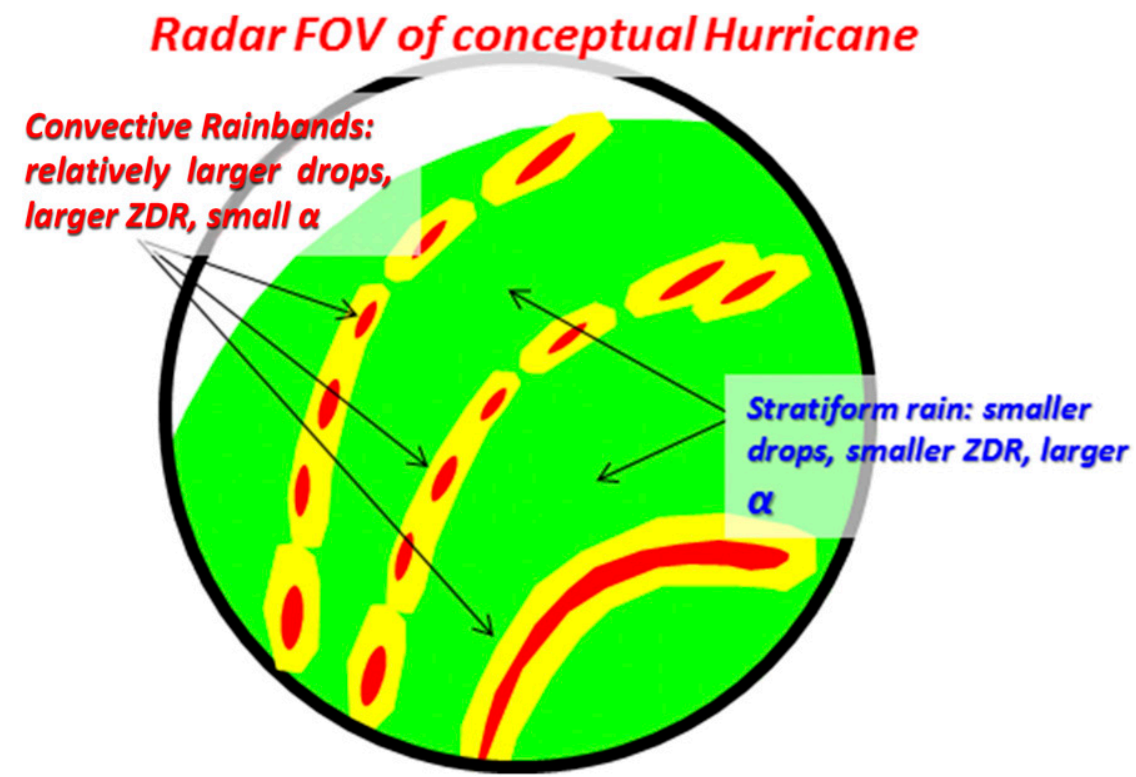

FIG. 9. Illustration of $Z_{\mathrm{DR}}$ and $\alpha$ variability in stratiform and convective rainfall for a conceptual hurricane within the radar FOV. In general, if both precipitation regimes are within the FOV, then the net $\alpha$ may be too high for convective cells and too low in stratiform rain.

be responsible for the positive QPE bias. However, this particular case example illustrates the importance of accurate detection of the three-dimensional melting layer structure. In a future, more sophisticated approach for determining melting layer structure utilizing $\rho_{\mathrm{hv}}$ and two-dimensional numerical model data will be explored in a more advanced version of the algorithm that is currently under development. Despite all these challenges, the $R(A)_{\text {adj } \_\alpha}$ QPE performed better than the operational dual-pol QPE during Hurricane Matthew.
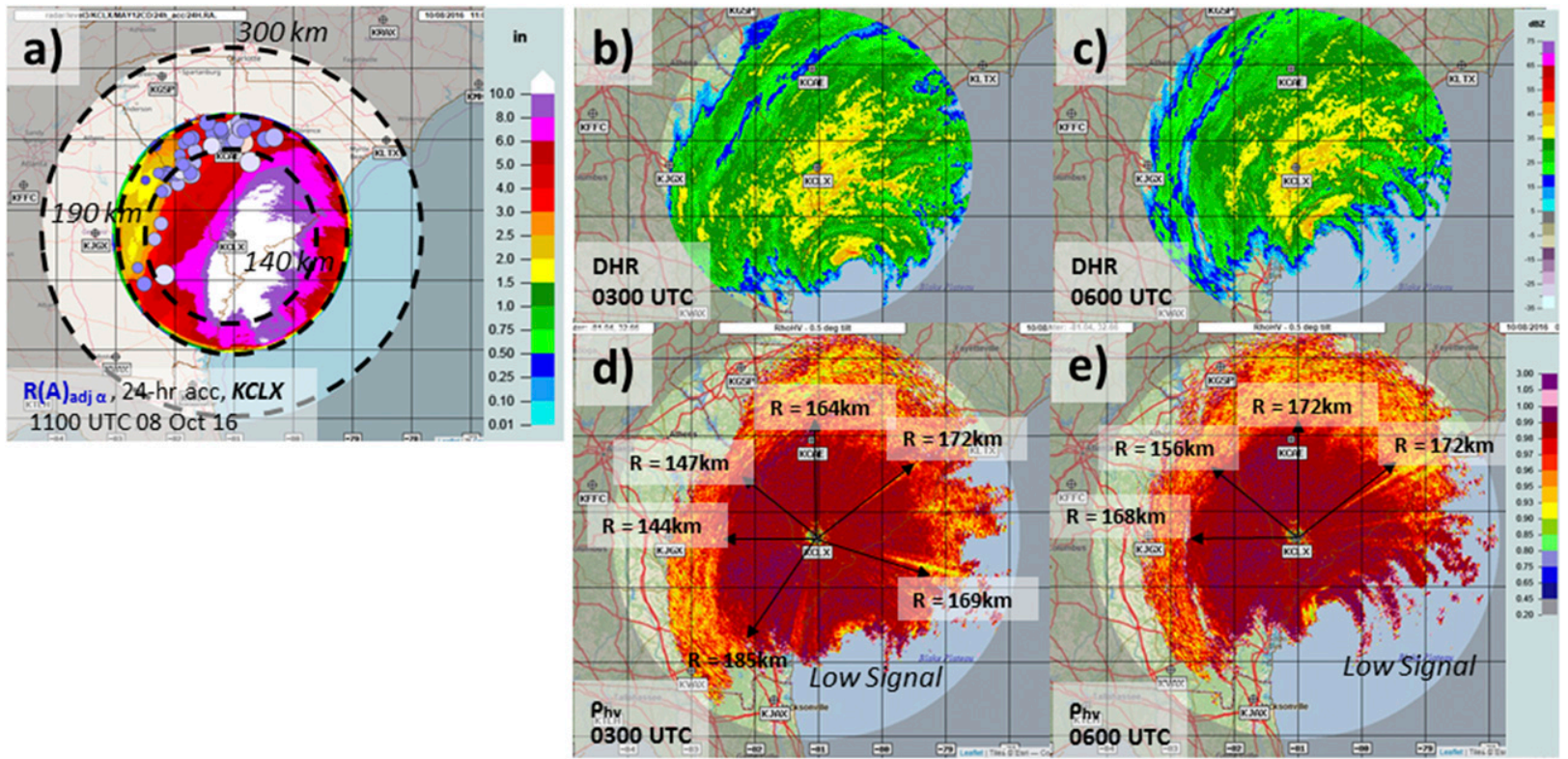

FIG. 10. (a) The 24-h $R(A)_{\text {adj }_{\alpha} \alpha}$ QPE/gauge bias bubble image for the 24-h period ending 1100 UTC 8 Oct 2016; (b),(c) digital hybrid scan reflectivity (DHR) and (d),(e) $\rho_{\mathrm{hv}}$ for 0300 and 0600 UTC 8 Oct 2016 . The arrows in (d) and (e) denote approximate distances the melting layer bottom is from the radar. Only gauge bias bubbles with distance $>120 \mathrm{~km}$ are shown in (a). Per standard procedure for WSR-88D radars, DHR and $\rho_{\mathrm{hv}}$ data are extended out to 230 and $300 \mathrm{~km}$, respectively. 

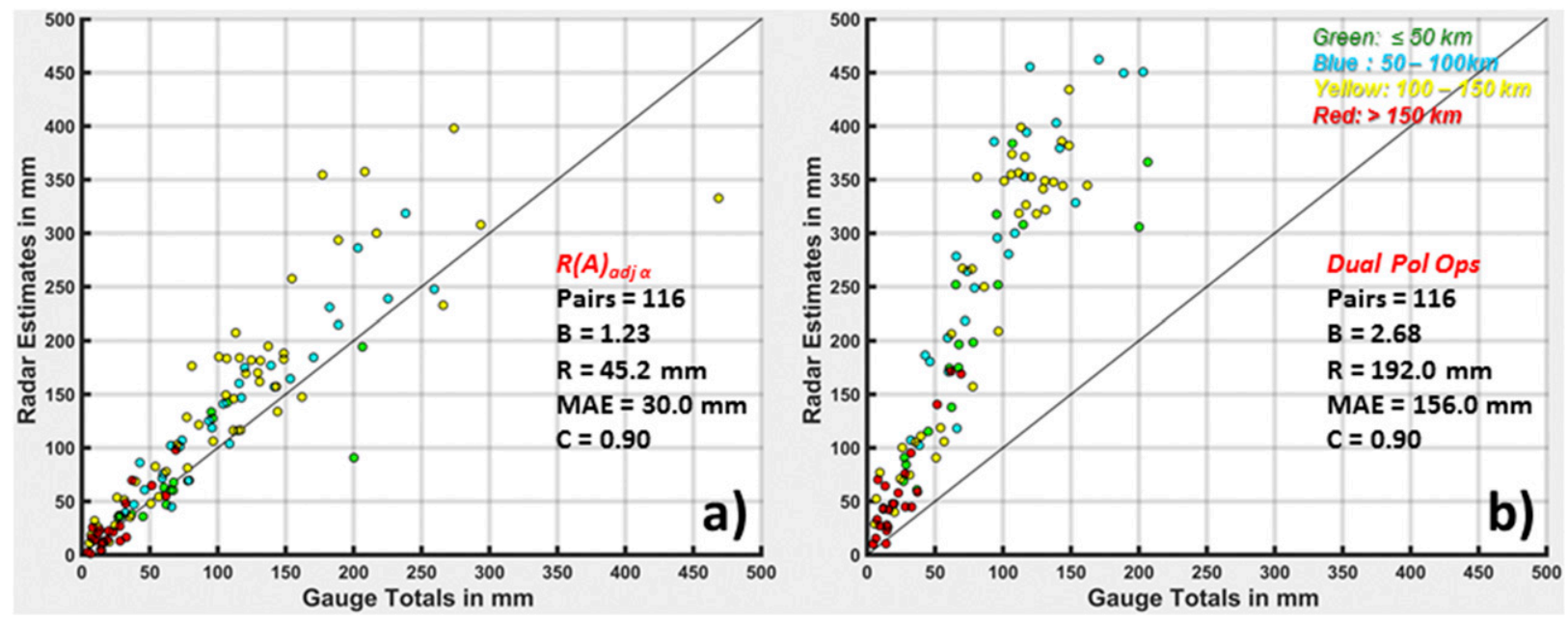

FIG. 11. (a) The $R(A)_{\text {adj_ } \alpha}$ and (b) operational dual-pol QPE as compared to quality controlled gauge totals using data from the KLIX radar for the 24-h period ending at 1200 UTC 12 Aug 2016. The legend is the same as in Fig. 2.

\section{d. $R(A)_{a d j \_\alpha}$ performance in the case of a poorly calibrated radar}

Between 10 and 13 August 2016, a slow westward moving tropical wave produced very heavy rainfall over the central U.S. Gulf Coast. In particular, catastrophic flooding occurred over the central and southern portions of the state of Louisiana during this period as a result of the copious amounts of rainfall. The 24-h period evaluated here ended at 1200 UTC 12 August 2016 with radar data collected from the WSR-88D radar in New Orleans, Louisiana (KLIX). During this period, radar reflectivity and differential reflectivity crosssection comparisons (Gourley et al. 2003) with neighboring radars indicated KLIX $Z$ and $Z_{\mathrm{DR}}$ were biased by $\sim 0.75 \mathrm{~dB} Z$ and $-1.25 \mathrm{~dB}$ respectively. The severely biased $Z_{\mathrm{DR}}$, while unusual, strongly impacted the performance of the dual-pol QPE algorithm which relies on accurate measurements of $Z$ and $Z_{\mathrm{DR}}$. Negatively biased $Z_{\mathrm{DR}}$ would significantly increase rainfall rates made by the dual-pol QPE algorithm (Cocks et al. 2016). Figure 11 shows the scatterplots of 24-h accumulations of $R(A)_{\text {adj_ } \alpha}$ and dual-pol QPEs versus quality controlled gauges. As expected, the dual-pol QPE exhibited very large errors and a radar-to-gauge bias ratio $>2.5$. Despite the severely miscalibrated $Z_{\mathrm{DR}}$, the $R(A)_{\operatorname{adj} \_\alpha} \mathrm{QPE}$ exhibited errors that are much lower than dual-pol QPE. This illustrates that the $Z_{\mathrm{DR}}$ bias did not impact the estimate of the $Z_{\mathrm{DR}}$ slope, and, therefore of the factor $\alpha$. Modest overestimation of rainfall by the $R(A)_{\text {adj_ } \alpha} \mathrm{QPE}$ algorithm might be attributed to the use of a single $\alpha$ for the whole radar coverage area and, possibly, to the tipping-bucket gauge undercatch (primarily due to the time required for the bucket to tip) as explained earlier.

\section{e. Example of $R(A)_{\text {adj_ } \alpha}$ performance in regions of partial blockage}

Figure 12 shows the maps of 24-h rain accumulations estimated from the dual-pol QPE and $R(A)_{\text {adj_ } \alpha}$ QPE in areas of partial beam blockage around the Columbus Air Force Base, Mississippi (KGWX), Wilmington, North Carolina (KLTX), and Columbia, South Carolina (KCAE), radars. Most of the blockages are due to the presence of tall trees growing very close to the radar. These are not accounted for in digital elevation maps routinely used for blockage correction. In each case, the new $R(A)_{\text {adj_ } \alpha}$ QPE generally did a better job filling in the partial blockages than the dual-pol QPE algorithm despite the fact the prototype algorithm only used data from the $0.5^{\circ}$ elevation tilt. The one exception to this is shown in Figs. 12c and 12d where the dual-pol QPE algorithm better filled the partial beam blockage sector southwest of the KLTX radar. The reason for this was the dual-pol algorithm utilized a higher elevation tilt to estimate QPE in this region, likely set up by the local forecast office. Otherwise, in the other partial blockage regions the $R(A)$ QPE performed better by filling in partial beam blockage sector. Figures $13 \mathrm{a}$ and $13 \mathrm{~b}$ display the 24-h QPE versus gauge scatterplots for the partial blockage region around the KCAE radar (Figs. 12e,f). Within the partial blockage region, the $R(A)_{\text {adj_ } \alpha}$ QPE exhibits a much better $(0.97)$ gauge to radar bias ratio with $>40 \%$ lower errors.

\section{Summary and conclusions}

This paper is the second of two documenting the development and validation of a prototype QPE algorithm 


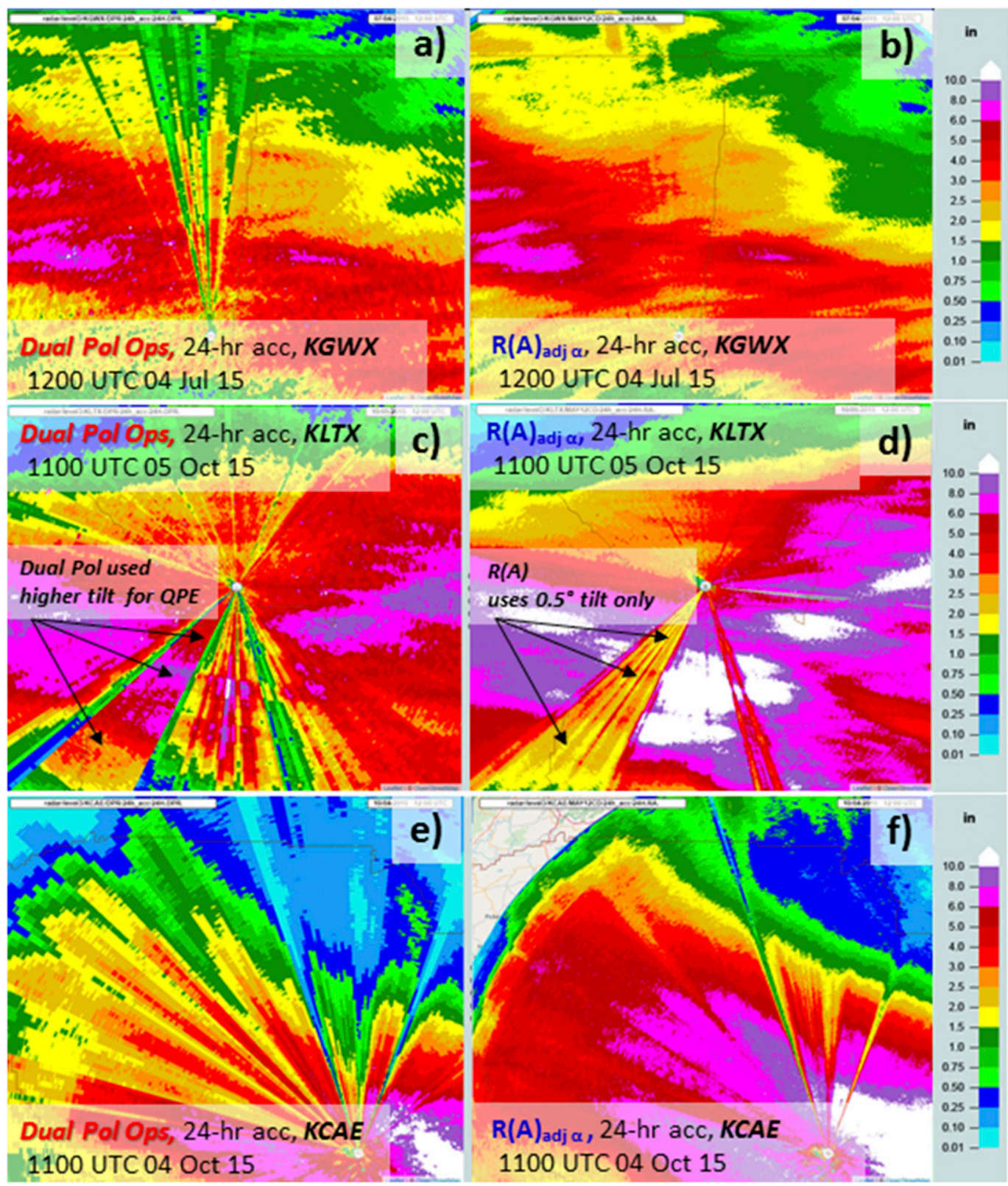

FIG. 12. (a),(c),(e) The 24-h accumulations of dual-pol and (b),(d),(f) $R(A)_{\text {adj_} \_\alpha}$ QPE in regions of partial blockage around the (top) KGWX, (middle) KLTX, and (bottom) KCAE radars for 24-h accumulations ending at the time labeled in each panel.

utilizing specific attenuation that was based upon the work of Ryzhkov et al. (2014), Wang et al. (2014), and Part I. A large dataset comprising 49 precipitation events east of the Rocky Mountains from the 2014 through 2016 warm seasons was used to validate the performance of the two versions of the $R(A)$ algorithm: with fixed and variable factor $\alpha=A / K_{\mathrm{DP}}$ used in computation of specific attenuation $A$. The statistics of $\alpha$ for different rain types was examined in the course of the study. The median value of $\alpha$ during tropical and continental precipitation regimes was determined from the analysis of 9 tropical and 13 continental precipitation events. The median $\alpha$ for tropical (continental) rain regimes was found to have values of $0.028(0.018) \mathrm{dB}$ per degree. The reason for the differences is because for tropical rain $A$ is high but $K_{\mathrm{DP}}$ is low due to the abundance of small drops having a nearly spherical shape.

This paper also demonstrated the importance of using a real time estimated $\alpha$ as opposed to assuming a fixed value when estimating precipitation via specific attenuation. 

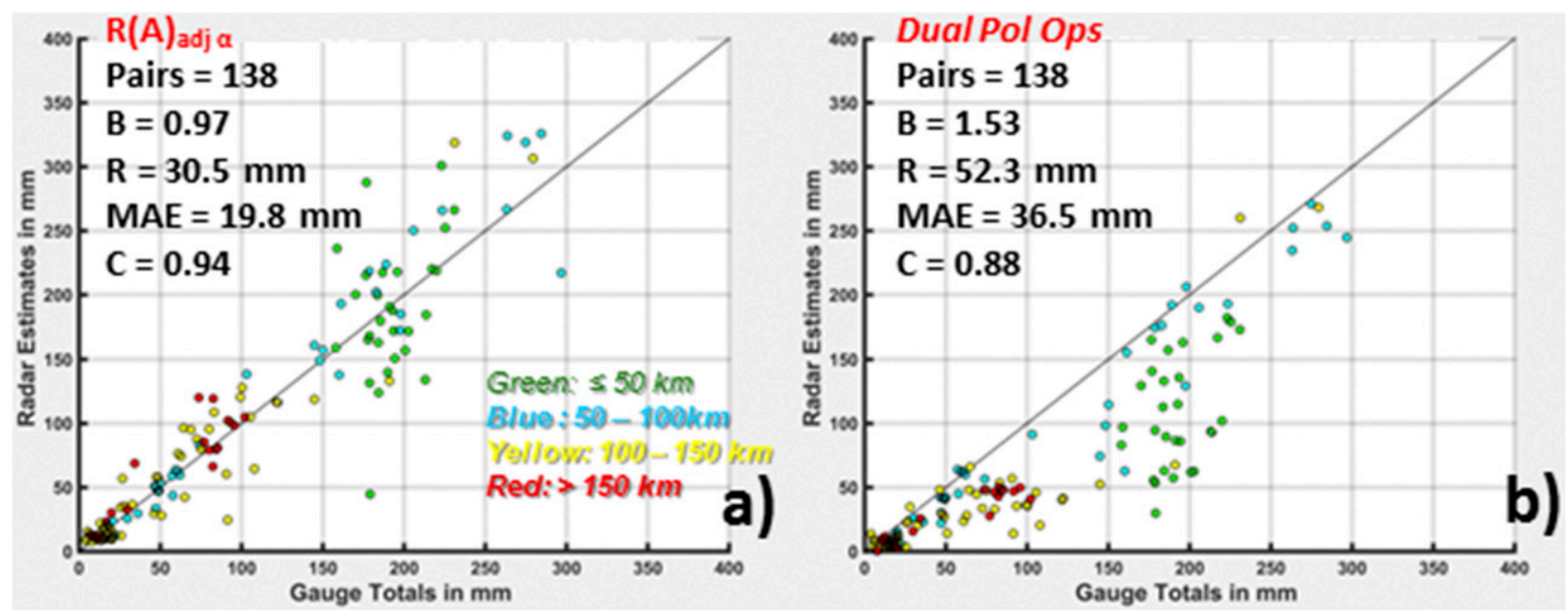

FIG. 13. (a) The $R(A)_{\text {adj_ } \alpha}$ and (b) operational dual-pol QPE as compared to quality controlled gauge totals using data from the KCAE radar for the 24-h period ending 1100 UTC 4 Oct 2015. Many of the dual-pol QPE underestimates occurred in the partial blockage region $\left(280^{\circ}-030^{\circ}\right.$ azimuth) around the KCAE radar. The legend is the same as in Fig. 2.

QPE derived using a fixed $\alpha$ of $0.015 \mathrm{~dB}$ per degree, $R(A)_{\text {fix }}$ ${ }_{\alpha}$, exhibited significantly higher standard errors and a larger bias than QPE derived using factor $\alpha$ updated every $0.5^{\circ}$ tilt $\left[R(A)_{\text {adj_ } \alpha}\right]$. Further, comparison of the $R(A)_{\text {adj_ } \alpha}$ QPE with the operational dual-pol QPE estimates indicated the former had lower errors, less variability, and exhibited significantly better estimates for moderate-to-heavy precipitation events (with gauge totals $>150 \mathrm{~mm}$ ).

The new QPE performance was more closely examined for three precipitation events: a severe convective storm event over the Great Plains, Hurricane Matthew impacting the Georgia/Carolina coasts, and a tropical wave affecting the central Gulf Coast where $Z_{\mathrm{DR}}$ was poorly calibrated. In each case, the $R(A)_{\text {adj } \_\alpha}$ QPE performed better than the operational dual-pol QPE, especially for the higher rainfall totals. Calibration challenges were present for two of the cases, the most noteworthy was the severely biased $Z_{\mathrm{DR}}$ in the tropical wave example. As long as the $Z$ and $Z_{\mathrm{DR}}$ biases affect the entire radar FOV, then the estimation of the parameter $\alpha$, critical for path integrated attenuation calculations, is not affected. Statistical analysis of the comparative performance of the $R(A)_{\text {adj }}$ and the dual-pol QPE algorithm currently implemented on the WSR-88D radar network indicates obvious advantages of the attenuation-based methodology.

Occasional overestimation of rainfall with $R(A)_{\text {adj_ } \alpha}$ QPE is likely attributed to the use of a single value of net $\alpha$ indiscriminantly in the areas of convective and stratiform rain. Another possible reason for positive QPE bias is contamination by the melting layer if its height is not correctly determined. Future work will further reduce the melting layer contamination through the use of model data and cross-correlation coefficient data to refine the melting layer height. Finally, comparisons of the $R(A)_{\text {adj_ } \alpha}$ estimates to dual-pol QPE within regions of partial beam blockage showed the former is much more efficient in filling the gaps caused by trees growing very close to the radar. For one of those cases, a comparison of the two QPEs to gauge data showed the $R(A)_{\text {adj_ } \alpha}+R\left(K_{\mathrm{DP}}\right)$ exhibited significantly lower error and bias than the operational dual-pol QPE despite the former using only the lowest tilt.

Currently the Radar Operations Center is testing the new $R(A)$ QPE algorithm for operational use on the WSR-88D network. Further, the new QPE algorithm is now the foundation of a developmental MRMS QPE product that utilizes $R(A)$ precipitation estimates below the melting layer, $R\left(K_{\mathrm{DP}}\right)$ estimates where hail likely and $R(Z)$ within and above the melting layer as initially described by Zhang et al. (2017).

Acknowledgments. Funding was provided by NOAA/ Office of Oceanic and Atmospheric Research under NOAA-University of Oklahoma Cooperative Agreement NA16OAR4320115, U.S. Department of Commerce, as well as the Radar Operations Center technology transfer memorandum of understanding.

\section{REFERENCES}

Berkowitz, D. S., J. A. Schultz, S. Vasiloff, K. L. Elmore, C. D. Payne, and J. B. Boettcher, 2013: Status of dual pol QPE in the WSR-88D network. 27th Conf. on Hydrology, Austin, TX, Amer. Meteor. Soc., 2.2, https://ams.confex.com/ams/93Annual/webprogram/ Paper221525.html.

Boodoo, S., D. Hudak, A. Ryzhkov, P. Zhang, N. Donaldson, D. Sills, and J. Reid, 2015: Quantitative precipitation estimation 
from a C-band dual-polarized radar for the 8 July 2013 flood in Toronto, Canada. J. Hydrometeor., 16, 2027-2044, https://doi.org/10.1175/JHM-D-15-0003.1.

Bringi, V. N., V. Chandrasekar, N. Balakrishnan, and D. S. Zrnic, 1990: An examination of propagation effects in rainfall on polarimetric variables at microwave frequencies. J. Atmos. Oceanic Technol., 7, 829-840, https://doi.org/10.1175/1520-0426(1990) 007<0829:AEOPEI $>2.0$.CO;2.

—, T. D. Keenan, and V. Chandrasekar, 2001: Correcting C-band radar reflectivity and differential reflectivity data for rain attenuation: A self-consistent method with constraints. IEEE Trans. Geosci. Remote Sens., 39, 1906-1915, https:// doi.org/10.1109/36.951081.

Cocks, S., S. Martinaitis, B. Kaney, J. Zhang, and K. Howard, 2016: MRMS QPE performance during the 2013/14 cool season. J. Hydrometeor., 17, 791-810, https://doi.org/10.1175/ JHM-D-15-0095.1.

_ J. Zhang, S. Martinaitis, Y. Qi, B. Kaney, and K. Howard, 2017: MRMS QPE performance east of the Rockies during the 2014 warm season. J. Hydrometeor., 18, 761-775, https:// doi.org/10.1175/JHM-D-16-0179.1.

Diederich, M., A. V. Ryzhkov, C. Simmer, P. Zhang, and S. Tromel, 2015: Use of specific attenuation for rainfall measurement at $\mathrm{X}$-band radar wavelengths. Part II: Rainfall estimation and comparison with rain gauges. J. Hydrometeor., 16, 503-516, https://doi.org/10.1175/JHM-D-14-0067.1.

Droegemeier, K. K., and Coauthors, 2000: Hydrological aspects of weather prediction and flood warnings: Report on the Ninth Prospectus Development Team of the U.S. Weather Research Program. Bull. Amer. Meteor. Soc., 81, 2665-2680, https://doi.org/10.1175/1520-0477(2000)081<2653:EFITST> 2.3.CO;2.

Duchon, C. E., and G. R. Essenberg, 2001: Comparative rainfall observations from pit and aboveground rain gauges with and without wind shields. Water Resour. Res., 37, 3253-3263, https:// doi.org/10.1029/2001WR000541.

_ - and C. J. Biddle, 2010: Undercatch of tipping-bucket gauges in high rain rate events. $A d v$. Geosci., 25, 11-15, https://doi.org/ 10.5194/adgeo-25-11-2010.

_ C. C. Fiebrich, and D. Grimsley, 2014: Using high-speed photography to study undercatch in tipping-bucket rain gauges. J. Atmos. Oceanic Technol., 31, 1330-1336, https://doi.org/ 10.1175/JTECH-D-13-00169.1.

— C. A. Fiebrich, and B. G. Illston, 2017: Observing the May 2015 record rainfall at Norman, Oklahoma, using various methods. J. Hydrometeor., 18, 3043-3049, https://doi.org/ 10.1175/JHM-D-17-0137.1.

Efron, B., and R. J. Tishirani, 1993: Permutation tests. An Introduction to the Bootstrap. Chapman \& Hall, 202-218.

Fiebrich, C., C. Morgan, and A. McCombs, 2010: Quality assurance procedures for mesoscale meteorological data. J. Atmos. Oceanic Technol., 27, 1565-1582, https://doi.org/10.1175/ 2010JTECHA1433.1.

Giangrande, S., and A. Ryzhkov, 2008: Estimation of rainfall based on the results of polarimetric echo classification. J. Appl. Meteor., 47, 2445-2462, https://doi.org/10.1175/2008JAMC1753.1.

_ S. Collis, A. Theisen, and A. Tokay, 2014: Precipitation estimation from the ARM distributed radar network during the MC3E campaign. J. Appl. Meteor. Climatol., 53, 2130-2147, https://doi.org/10.1175/JAMC-D-13-0321.1.

Gourley, J. J., B. Kaney, and R. A. Maddox, 2003: Evaluating the calibrations of radars: A software approach. 31st Int. Conf. on Radar Meteorology, Seattle, WA, Amer. Meteor. Soc.,
P3C.1, https://ams.confex.com/ams/32BC31R5C/techprogram/ paper_64171.htm.

Groisman, P. Ya., and D. R. Legates, 1994: The accuracy of United States precipitation data. Bull. Amer. Meteor. Soc., 75, 215-227, https:// doi.org/10.1175/1520-0477(1994)075<0215:TAOUSP > 2.0.CO;2.

Kim, D., B. Nelson, and D. J. Seo, 2009: Characteristics of reprocessed Hydrometeorological Automated Data System (HADS) hourly precipitation data. Wea. Forecasting, 24, 1287-1296, https:// doi.org/10.1175/2009WAF2222227.1.

Krajewski, W. F., G. Villarini, and J. A. Smith, 2010: Radarrainfall uncertainties: Where are we after thirty years of effort? Bull. Amer. Meteor. Soc., 91, 87-94, https://doi.org/ 10.1175/2009BAMS2747.1.

Martinaitis, S. M., 2008: Effects of multi-sensor radar and rain gauge data on hydrologic modeling in relatively flat terrain. M.S. thesis, Dept. of Meteorology, Florida State University, 99 pp., http://purl.flvc.org/fsu/fd/FSU_migr_etd-2696.

_ S. B. Cocks, Y. Qi, B. Kaney, J. Zhang, and K. Howard, 2015: Understanding winter precipitation impacts on automated gauges within a real-time system. J. Hydrometeor., 16, 23452363, https://doi.org/10.1175/JHM-D-15-0020.1.

Reges, H. W., N. Doesken, J. Turner, N. Newman, A. Bergantino, and Z. Scwalbe, 2016: CoCoRaHS: The evolution and accomplishments of a volunteer rain gauge network. Bull. Amer. Meteor. Soc., 97, 1831-1846, https://doi.org/10.1175/BAMS-D14-00213.1.

Ryzhkov, A. V., M. Diederich, P. Zhang, and C. Simmer, 2014: Potential utilization of specific attenuation for rainfall estimation, mitigation of partial beam blockage, and radar networking. J. Atmos. Oceanic Technol., 31, 599-619, https:// doi.org/10.1175/JTECH-D-13-00038.1.

Sieck, L. C., S. J. Burges, and M. Steiner, 2007: Challenges in obtaining reliable measurements of point rainfall. Water Resour. Res., 43, W01420, https://doi.org/10.1029/2005WR004519.

Smith, J. A., D. J. Seo, M. L. Baeck, and M. D. Hudlow, 1996: An intercomparison study of NEXRAD precipitation estimates. Water Resour. Res., 32, 2035-2046, https://doi.org/10.1029/ 96WR00270.

Steiner, M., J. A. Smith, S. J. Burges, C. V. Alonso, and R. W. Darden, 1999: Effect of bias adjustment and rain gauge data quality control on radar rainfall estimation. Water Resour. Res., 35, 2487-2503, https://doi.org/10.1029/ 1999WR900142.

Tang, L., J. Zhang, C. Langston, J. Krause, K. Howard, and V. Lakshmanan, 2014: A physically based precipitationnonprecipitation radar echo classifier using polarimetric and environmental data in a real-time national system. Wea. Forecasting, 29, 1106-1119, https://doi.org/10.1175/WAF-D13-00072.1.

Testud, J., E. Le Bouar, E. Obligis, and M. Ali-Mehenni, 2000: The rain profiling algorithm applied to polarimetric weather radar. J. Atmos. Oceanic Technol., 17, 332-356, https://doi.org/10.1175/ 1520-0426(2000)017<0332:TRPAAT>2.0.CO;2.

Wang, Y., P. Zhang, A. Ryzhkov, J. Zhang, and P. Chang, 2014: Utilization of specific attenuation for tropical rainfall estimation in complex terrain. J. Hydrometeor., 15, 2250-2266, https:// doi.org/10.1175/JHM-D-14-0003.1.

, S. Cocks, P. Zhang, A. Ryzhkov, J. Zhang, and K. Howard, 2019: A prototype quantitative precipitation estimation algorithm for operational S-band polarimetric radar utilizing specific attenuation and specific differential phase. Part I: Algorithm description. J. Hydrometeor., 20, 985-997, https:// doi.org/10.1175/JHM-D-18-0071.1. 
Wilks, D. S., 2006: Statistical Methods in the Atmospheric Sciences. 2nd ed. International Geophysics Series, Vol. 100, Academic Press, 648 pp.

Wilson, J. W., and E. A. Brandes, 1979: Radar measurement of rainfall: A summary. Bull. Amer. Meteor. Soc., 60, 1048-1058, https:// doi.org/10.1175/1520-0477(1979)060<1048:RMORS > 2.0.CO;2.

Zhang, J., and Y. Qi, 2010: A real-time algorithm for the correction of bright band effects in radar-derived QPE. J. Hydrometeor., 11, 1157-1171, https://doi.org/10.1175/2010JHM1201.1.

K. Howard, C. Langston, and B. Kaney, 2012: Radar Quality Index (RQI) - A combined measure for beam blockage and VPR effects in a national network. IAHS Publ., 351, 388-393.

— quantitative precipitation estimation: Initial operating capabilities. Bull. Amer. Meteor. Soc., 97, 621-638, https://doi.org/ 10.1175/BAMS-D-14-00174.1.

—, and Coauthors, 2017: MRMS dual-polarization radar synthetic QPE. 38th Conference on Radar Meteorology, Chicago, IL, Amer. Meteor. Soc., 22B.3, https://ams.confex.com/ams/ 38RADAR/webprogram/Paper320875.html. 